\title{
The Diagnosis and Treatment of Celiac Disease
}

\author{
Detlef Schuppan, Klaus-Peter Zimmer
}

\section{SUMMARY}

Background: Celiac disease is an inflammatory disease of the small intestine with a prevalence of roughly $0.5 \%-1 \%$. Its symptoms arise in response to gluten consumption by genetically predisposed persons (HLA-DQ2/8). The autoantigen tissue transglutaminase (TG2) plays an important role in the pathogenesis of celiac disease.

Methods: Selective review of pertinent literature, including guidelines from Germany and abroad.

Results: Celiac disease can present at any age with gastrointestinal or extraintestinal manifestations (e.g., malabsorption or Duhring's dermatitis herpetiformis); it can also be found in association with other (auto-)immune diseases, such as type 1 diabetes. Most cases are oligosymptomatic. The wide differential diagnosis includes food intolerances, intestinal infections, and irritable bowel syndrome, among other conditions. The definitive diagnosis requires the demonstration of celiac disease-specific autoantibody to TG2 (endomysium), which is over $90 \%$ sensitive and far over $90 \%$ specific, and the characteristic histologic lesions of the small-bowel mucosa and remission on a gluten-free diet.

Conclusion: An understanding of celiac disease ought to inform everyday clinical practice in all medical disciplines, because this is a common condition with diverse manifestations that can be effectively diagnosed and easily treated for the prevention of both acute and long-term complications. Patients should follow a strictly gluten-free diet for life.

\section{Cite this as:}

Schuppan D, Zimmer KP: The diagnosis and treatment of celiac disease. Dtsch Arztebl Int 2013; 110(49): 835-46. DOI: 10.3238/arztebl.2013.0835
Institute of Translational Immunology, Johannes Gutenberg University, Mainz, and Division of Gastroenterology, Beth Israel deaconess Medical Center, Harvard Medical School, Boston, MA, USA: Prof. Dr. med. Dr. rer. nat. Schuppan Center for Pediatric and Adolescent Medicine, Justus Liebig University, Gießen: Prof. Dr. med. Zimmer
C. rains were first domesticated for regular consumption in the human diet only about 10000 years ago in Mesopotamia, and about 3000 years later in central Europe. In the second century AD, Aretaeus of Cappadocia described an "abdominal" (koiliakos) disease that was apparently related to nutrition, but S. J. Gee (London, 1888) is considered to be the first describer of what we now know as celiac disease. This disease was much feared in the early decades of the $20^{\text {th }}$ century because of its high mortality, which ran as high as $30 \%$ (e1).

The pediatrician K. W. Dicke of Utrecht and the Hague, in the early 1930s, was the first to link celiac disease to wheat consumption (e2). He witnessed the confirmation of his hypothesis when his patients' symptoms improved during the grain shortages prevailing toward the end of the Second World War.

In the early 1950s, Dicke, Weyers and van de Kamer characterized gluten (the storage proteins of wheat) as the precipitating factor of the manifestations of celiac disease (e2).

The morphological correlate of celiac disease-villous atrophy with crypt hyperplasia-was studied in detail by Paulley (Ipswich, 1954) and by Shiner (London, 1956). Anti-gliadin antibodies were discovered by Berger (Basel, 1958), anti-endomysium antibodies by Chorzelski (Warsaw, 1983). A further milestone was the discovery of the autoantigen of celiac disease, tissue transglutaminase (TG2) (1).

Even though precise and rational diagnostic evaluation is now possible, celiac disease remains an underdiagnosed condition, probably because of its broad clinical spectrum and the underuse of serologic screening $(2,3)$.

The typical latency from the onset of symptoms to diagnosis is now about four years (e3). This is all the more regrettable because very effective treatment is

\section{Definition}

Celiac disesae is a common inflammatory disease of the small bowel that is precipitated by the consumption of foods that contain gluten. 
available that can prevent further manifestations, i.e., a gluten-free diet.

This article is based on the evidence-based guidelines issued in recent years by the Agency for Healthcare Research and Quality (AHRQ, 2004), the American Gastroenterological Association (AGA, 2006), the North American Society for Pediatric Gastroenterology, Hepatology, and Nutrition (NSPGHAN, 2005), the National Institute for Health and Clinical Excellence (NICE, 2009), and the European Society of Paediatric Gastroenterology, Hepatology, and Nutrition (ESPGHAN, 2012) (3-7), and on further pertinent publications of the last 10 years that were retrieved by a selective search in the PubMed database. The search term was "celiac disease," with the inclusion criteria "diagnosis," "therapy," “epidemiology," "pathogenesis," and "guideline."

\section{Learning objectives}

This article should enable the reader to:

- acquire a better understanding of the etiology and pathogenesis of this systemic disease,

- recognize the heterogeneous manifestations of celiac disease early on in its course, perform a rational basic diagnostic evaluation, and then order the necessary confirmatory tests,

- assess the indications, therapeutic potential, and limitations of a gluten-free diet, and

- know the spectrum of complications of celiac disease and how they can be prevented.

\section{Definition}

Celiac disease (synonym: endemic sprue) is a common autoimmune inflammatory disease of the small bowel that can also have systemic manifestations. It is precipitated by the consumption of foods that contain gluten, including wheat, barley, rye, and spelt. In HLA-DQ2/8 positive patients, the diagnosis is confirmed by the demonstration of serum autoantibodies against endomysium (EMA) or tissue transglutaminase (TG2); a characteristic histological picture in the duodenum (inflammatory infiltrate, crypt hyperplasia, villous atrophy); and remission of the clinical and serologic findings on a gluten-free diet. Celiac disease can present in the classic way-with severe diarrhea and malabsorption - or else (more commonly) with lesser or atypical manifestations; the clinical picture of celiac disease can also be dominated by the other autoimmune conditions that are associated with it $(5,8)$.

\section{Pathogenesis}

Celiac disease is one of the better characterized diseases of the immune system. The affected patients all have the following:

- a genetic predisposition (either HLA-DQ2 or HLA-DQ8);

- a well-defined precipitating factor (gluten);

- highly sensitive and specific autoantibodies against the naturally occurring human enzyme, tissue transglutaminase (TG2).

$\mathrm{TG} 2$ is an autoantigen that plays a central role in the pathogenesis of celiac disease: it potentiates the immunogenicity of the immunogenic gluten peptides through a chemical reaction in the small bowel (deamidation).

Gluten, the alcohol-soluble fraction of wheat protein, is consumed in large quantities (10-20 g per day) as part of the normal food intake. Some gluten peptides are not degraded by gastrointestinal enzymes (e4), but rather taken up across the epithelium of the small-bowel mucosa (9). There, they are presented on the antigen-presenting cells of persons with the HLA types HLA-DQ2 or HLA-DQ8 (about 90\% and 10\% of persons with celiac disease, respectively) and thereby stimulate gluten-specific T cells (Figure 1).

As part of this process, a neutral glutamine residue is deamidated through the activity of the enzyme and autoantigen TG2 to produce an acidic glutamic acid residue, thereby promoting the binding of gluten peptides to HLA-DQ2 or HLA-DQ8 and potentiating the inflammatory T-cell reaction (8). The activated T cells in the lamina propria and within the epithelium are cytotoxic, with effects including apoptosis of enterocytes, atrophic remodeling of the mucosa, and malabsorption.

Recently, amylase-trypsin inhibitors (ATI), which are resistance proteins found in wheat, rye, and barley, have been shown to activate the innate immune system in patients with celiac disease and in persons with non-celiac wheat intolerance (10).

Considering that $30 \%$ to $40 \%$ of the overall population carries either HLA-DQ2 or -DQ8, and that many other genetic predispositions have been identified in recent years that play a smaller role (about $3-4 \%$ overall, versus about $50 \%$ for HLA-DQ2/8), other influences are now thought to be potential precipitating factors for celiac disease, including early and massive gluten exposure, bowel infections, and drugs (8).

\section{Genetics}

Only persons with the genotype HLA-DQ2 or HLA-DQ8 can develop celiac disease.

\section{Autoantigen}

The autoantigen of celiac disease is tissue transglutaminase (TG2). 


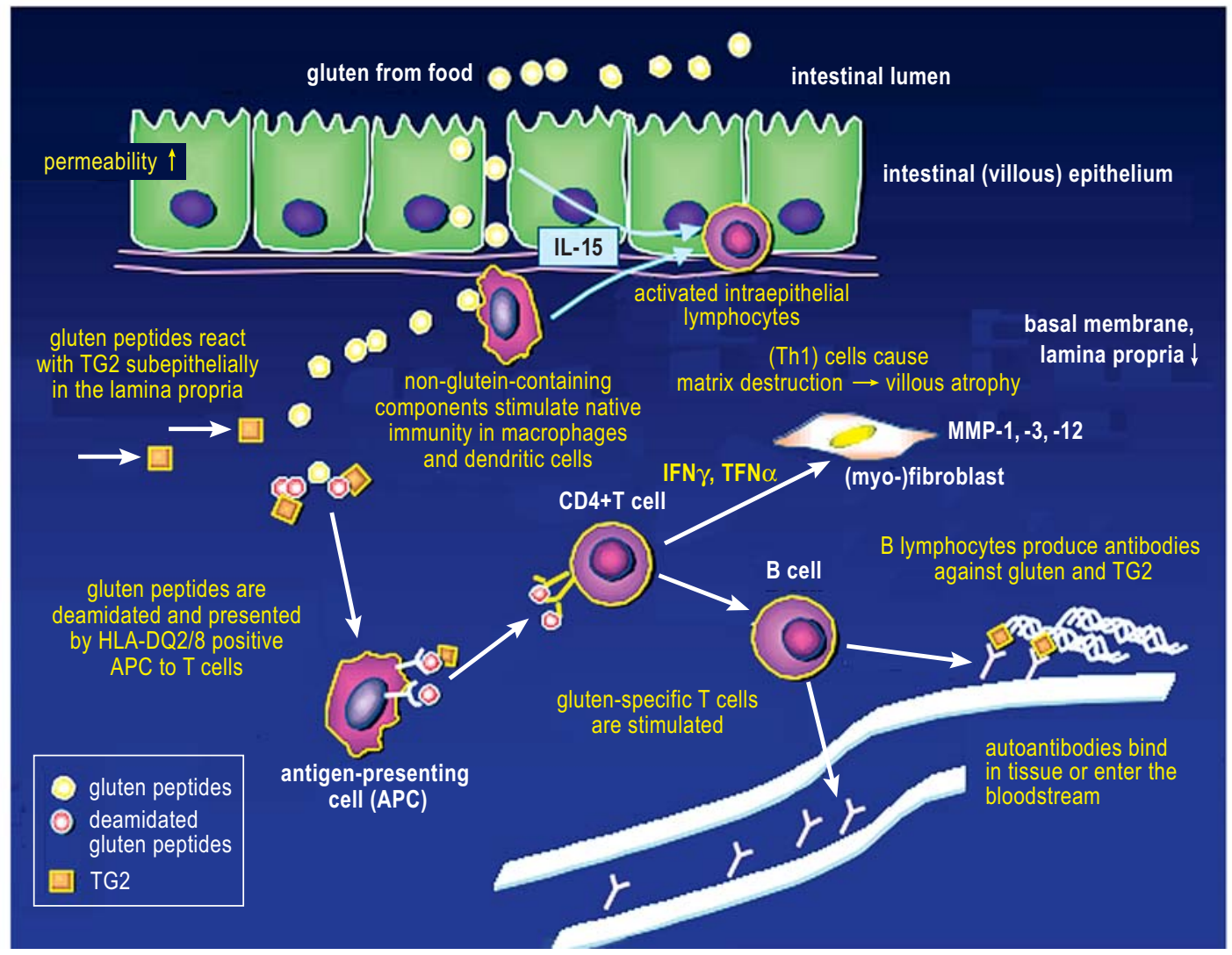

The pathogenesis of celiac disease. Gluten peptides are taken up across the intestinal epithelium, deamidated through the activity of tissue transglutaminase (TG2), and presented in the lamina propria by dendritic cells (among others), thereby activating gluten-specific cytotoxic T cells and T helper cells. IL-15 formed in intestinal epithelial and dendritic cells stimulates intraepithelial lymphocytes. Other cytokines of the typical immune reaction of celiac disease include, for example, IFN- $\gamma$, TNF- $\alpha$, IL-8, IL-18, and IL-21 (modified from 8). Yellow lettering is used for processes, white lettering for cells and proteins. MMP, matrix metalloproteinase.

\section{Epidemiology}

The prevalence of celiac disease could not be estimated with any degree of accuracy until serologic tests for IgAEMA and IgA-anti-TG2 became available, together with subsequent confirmation of the suspected diagnosis by endoscopic biopsy of the small bowel in antibody-positive subjects. The two serologic tests are highly sensitive (96.1\% and $93.1 \%$, respectively) and highly specific $(97.4 \%$ and $96.3 \%)(7$, e5). Studies have now revealed a prevalence of $0.5 \%$ to $1.0 \%$ among Americans and
Europeans, as well as in the populations of Australia, North Africa, the Middle East, India, and probably also northern China (depending on the prevalence of HLADQ2 and HLA-DQ8 (11). In some populations, including in Finland and Mexico and among the Sahrawi children of North Africa, the prevalence lies between $2 \%$ and $5 \%$ (11, 12). Celiac disease can manifest itself clinically at any age. At present, it is diagnosed in roughly equal measure in adults and children; it is now more commonly diagnosed in school-age than in preschool children (11, e6-e7).

\section{Age of onset}

Celiac disease can manifest itself clinically at any age. At present, it is diagnosed in roughly equal measure in adults and children; it is now more commonly diagnosed in school-age than in preschool children.

\section{Epidemiology}

There have been only a few good epidemiological studies on celiac disease in Germany. In 1995/96, its prevalence (biopsy-confirmed) in the Dresden area was estimated to be at least $0.2 \%$ based on the screening of 3004 schoolchildren. 


\section{Screening of persons at risk for celiac disease*}

\section{- Asymptomatic/atypical manifestations}

- first-degree relatives

$10-20 \%$

- Down syndrome

$5-12 \%$

- Ullrich-Turner syndrome

- Williams-Beuren syndrome

$2-5 \%$

- selective IgA deficiency

- autoimmune thyroiditis

$2-8 \%$

$3-7 \%$

- autoimmune hepatitis (children)

$12-13 \%$

- type 1 diabetes

$2-12 \%$

- juvenile chronic arthritis

$1.5-2.5 \%$

\section{- Oligosymptomatic manifestations}

- failure to thrive

- weight loss

- short stature / growth retardation

- delayed puberty (amenorrhea)

- iron-deficiency anemia

- anorexia

- dyspeptic symptoms (nausea/vomiting)

- chronic, recurrent abdominal pain (bloating)

- chronic constipation

- chronic fatigue/diminished performance

- recurrent aphthous sores

- chronic/intermittent diarrhea

- difficulty concentrating

- depressed mood

- chronic headache

- elevated transaminases

- tooth-enamel defects

- osteoporosis/osteopenia

Because of the high prevalence of celiac disease in persons with these conditions (in percent), such persons should be screened for celiac disease (testing for TG2 antibodies ideally including HLA-DQ2/8) even if they manifest none of its characteristic symptoms and signs.

Oligosymptomatic patients, i.e., those who manifest only a few of the symptoms and signs of celiac disease, should undergo serologic testing for it if their problems are not adequately explained by an alternative diagnosis.

*modified from $(7$, e15)
There have been only a few good epidemiological studies on celiac disease in Germany. In 1995/96, the prevalence of biopsy-confirmed celiac disease in the Dresden area was estimated to be at least $0.2 \%$, based on the screening of 3004 schoolchildren (13). In the Augsburg and Ulm areas, studies of cohorts of 9201 and 2157 adults (the KORA/MONICA and EMIL studies, respectively) yielded prevalence figures of $0.3 \%$ and $0.4 \%$ (2, e8). Unpublished data of the German Health Interview and Examination Survey for Children and Adolescents (KiGGS) on 17000 children and adolescents studied from 2003 to 2006 indicate that seroprevalence is higher than this (Robert Koch Institute, personal communication).

It is not known why celiac disease is less common in Germany than elsewhere in Europe. Possible reasons include differences in nutrition (higher rate and longer duration of breastfeeding, lower intake of gluten in early childhood) or else the prevalence of infections (the hygiene hypothesis) $(14,15)$.

\section{Clinical features}

It has become rare for celiac disease to present in adults or in children with its classic manifestations - severe diarrhea and consequent weight loss with failure to thrive due to severe intestinal malabsorption (e9) (eTable). More than half of all diagnosed cases are oligosymptomatic or clinically atypical, associated (for example) with anemia, osteoporosis, musculoskeletal and neurological disorders, endocrinopathies, or skin diseases (e3, e12). Asymptomatic and oligosymptomatic forms with or without the typical pathological findings of celiac disease in the small-bowel mucosa, also called latent or potential celiac disease (7, e13), are mainly detected serologically by screening tests (16). Untreated celiac disease can worsen and is associated over the long term with a higher risk of gastrointestinal cancer, including intestinal T-cell lymphoma, which is a very rare disease in general (e14).

The extraintestinal manifestations of celiac disease may dominate the clinical picture, overshadowing the intestinal ones; if the correct diagnosis is made early, they often improve when the patient is put on a gluten-free diet (GFD). These manifestations may include (among others) hepatopathy, Duhring's dermatitis herpetiformis, IgA nephropathy, temporal-lobe epilepsy, cerebellar ataxia, peripheral neuropathy, pulmonary hemosiderosis, or nonspecific problems such as joint pain, exhaustion, headache, mood swings (depression), and constipation (Box 1).

\section{Extraintestinal organ involvement}

Alongside the characteristic gastrointestinal manifestations, patients with celiac disease also often have extraintestinal organ involvement and other autoimmune conditions.

\section{Complications}

If the patient does not adhere to a gluten-free diet, both malabsorption and extraintestinal complications may develop. 


\section{Associated autoimmunity}

A large-scale Italian study of patients with celiac disease revealed that $30 \%$ also suffered from autoimmune diseases such as type 1 diabetes, autoimmune thyroiditis (Hashimoto's disease, Graves' disease), and autoimmune hepatitis. Celiac disease thus constitutes an indication for further autoimmune diagnostic testing (17). This is because celiac disease shares a common primary genetic predisposition with other autoimmune diseases (HLADQ2 or HLA-DQ8, which are associated with HLADR3 and HLA-DR4) (18).

\section{Complications / refractory celiac disease}

Classic celiac disease has a very broad spectrum of complications (Box 2). If the patient does not adhere to a gluten-free diet, both malabsorption and extraintestinal complications may develop.

In rare cases, celiac disease in older patients fails to respond to a gluten-free diet, or else the symptoms and mucosal lesions reappear despite such a diet. While this may be due to inadequate adherence to the diet or to unintentional gluten intake, the differential diagnosis also includes rarer types of atrophic or inflammatory bowel disease. About one-third of all cases of this type are attributable to refractory celiac disease with villous atrophy (19). This condition, in turn, is subdivided into two types. In type 1, the phenotype of intraepithelial lymphocytes is normal, and treatment with mild immune suppressants (steroids, azathioprine) often helps. In type 2 , on the other hand, biopsy reveals the incipient proliferation of atypical monoclonal intraepithelial lymphocytes, and the treatment is more difficult. In three to five years, about half of these patients develop an overt intestinal T-cell lymphoma, a disease with a very poor prognosis: survival times range from a few months to a few years $(8$, 20, 21).

\section{Serologic diagnosis}

Serologic antibody tests are indicated for all persons in whom celiac disease is (even remotely) suspected, and for all persons known to be at risk for the disease (22). Patients should should eat gluten containing food for at least a few days or weeks before a serologic antibody test (as before a small-bowel biopsy), because serum antibodies have a half-life of 30 to 60 days. All tests have a negative predictive value near $100 \%$, i.e., normal values practically rule out active celiac disease (with classic histology and under the condition of normal gluten intake). Antibodies against native gliadin have a low

\section{BOX 2}

\section{The spectrum of complications of classic celiac disease}

- acute global/selective malabsorption (anemia and other consequences)

- somatic and psychosocial retardation

- impairment of quality of life

- infertility, miscarriage, preterm birth, low birth weight (32)

- osteoporosis (37)

- extraintestinal manifestations, e.g., neurological (cerebellar ataxia, peripheral neuropathy), renal (IgA nephropathy), pulmonary (pulmonary hemosiderosis)

- autoimmune diseases (type 1 diabetes, autoimmune thyroiditis) (17)

- cancer, particularly enteropathy-associated T-cell lymphoma (EATL) (38)

- increased mortality $(39,40)$

positive predictive value - in the range of $18 \%$ to $31 \%$, assuming a prevalence of $5 \%$ in persons at risk (22); on the other hand, under the same assumption, the average positive predictive values of anti-endomysium autoantibodies (EMA) and of IgA anti-TG2 andtibodies are $83 \%$ and $72 \%$, respectively (22). A TG2-ELISA can be performed in standardized fashion in any clinical laboratory, and TG2 is the main EMA autoantigen; therefore, TG2-ELISA is recommended as the primary serological screening test for celiac disease. The total IgA level should be measured before the test, because more than $2 \%$ of patients with celiac disease have a selective IgA deficiency, so that IgA autoantibody tests may be negative even in the face of active disease. If IgA deficiency is found, a test for IgG autoantibodies against deamidated gliadin peptides (IgG anti-DGP) is recommended; these peptides are formed in the small-bowel mucosa only in celiac disease, as the result of deamidation through the activity of TG2. The IgG anti-DGP test has an acceptable, but somewhat lower positive predictive value for the diagnosis of celiac disease (less than $70 \%)(22)$.

Occasionally, celiac-disease-specific antibodies are transiently detectable in genetically predisposed persons (23); moreover, in infants up to 24 months of age, the sensitivity of IgA antibodies against endomysium, TG2

\section{Serologic diagnosis}

Serologic evaluation preferably involves testing for IgA antibodies against TG2 (in some cases, also for antibodies against endomysium and deamidated gliadin peptides).

\section{Antibody detection in stool and saliva}

Antibody measurement in stool or saliva is of no value in the diagnostic evaluation of celiac disease, and testing for antibody against native (non-deamidated) gliadin is not advised. 


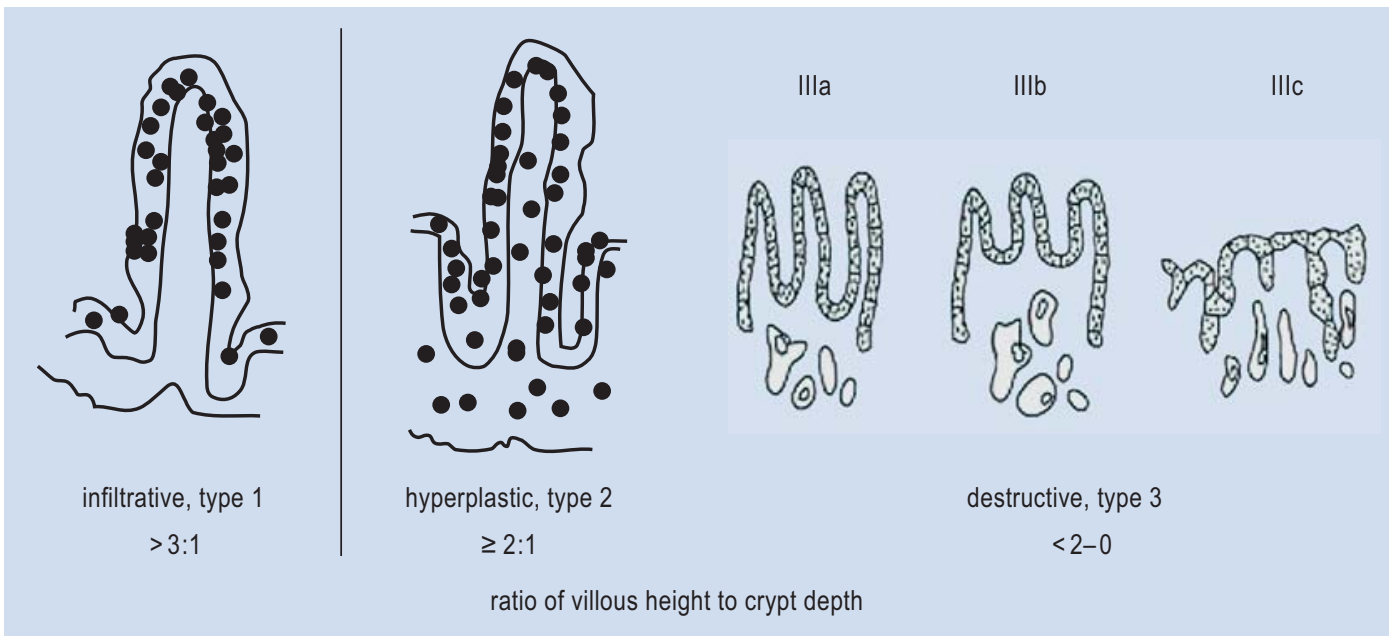

The mucosal lesions of celiac disease (Marsh-Oberhuber classification): the histologic changes of the intestinal mucosa consist of lymphocytic proliferation in the epithelium and the lamina propria, crypt hyperplasia, and lower height of the villi. A type 2 or type 3 lesion is required for the diagnosis of celiac disease. Modified from (e16)

and deamidated gliadin peptides is lower (24, e16). Antibody measurement in stool or saliva is of no value in the diagnostic evaluation of celiac disease. Testing for antibody against native (non-deamidated) gliadin is not advised either (7). There are now rapid tests for TG2 autoantibodies that resemble pregnancy tests and are cleverly marketed by being placed on store shelves next to glutenfree foods; these tests are much less accurate than laboratory tests. In the absence of confirmation of the results, interpretation by a medical specialist, and appropriate counseling, these tests generate more uncertainty than clarity and confer the risk of over- or undertreatment.

\section{Histology}

Endoscopy usually reveals grossly visible abnormalities in the proximal portion of the small intestine (scalloping of duodenal folds, mosaic mucosal pattern, and mucosal atrophy). The diagnosis is confirmed by histologic evaluation according to the Marsh classification (e17), with at least four biopsies taken from the four quadrants of the descending duodenum and, preferably, one or two more from the duodenal bulb. The mucosal lesions often display a mosaic pattern ("patchy lesions"), rather than covering the entire mucosal surface. In most cases, a characteristic Marsh III lesion is present, with stages Marsh III a-c (partial to total loss of villi) (25). The diagnosis of celiac disease is also considered to be confirmed if crypt hyperplasia is seen with at least 25 intraepithelial lymphocytes per 100 enterocytes in the absence of villous atrophy (a Marsh II lesion), as long as autoantibodies have been detected. A Marsh I lesion, i.e., isolated proliferation of intraepithelial lymphocytes with at least 25 per 100 epithelial cells, is a nonspecific finding with a positive predictive value of only about $15 \%$ (Figure 2) $(25,26)$. The value of immunohistochemical methods (mucosal IgA-TG2 deposition) is still debated.

It is important to note that the duodenal biopsy should be performed at roughly the same time as serologic testing for celiac disease, while the patient is symptomatic, and that a gluten-free diet should not be initiated until after the biopsy. Normal mucosal histology rules out celiac disease, but Marsh II lesions cannot be detected by gross inspection; as celiac disease is a common condition, it follows that biopsies should always be taken whenever a gastroduodenoscopy is performed. The tissue samples should be tangentially embedded for

\section{Histology}

The small intestinal mucosa of untreated persons with celiac disease usually displays villous atrophy (Marsh III), or, less commonly, isolated crypt hyperplasia (Marsh II), together with intraepithelial lymphocytic proliferation.

\section{Timing of biopsy}

The duodenal biopsy should be performed at roughly the same time as serologic testing for celiac disease, while the patient is symptomatic, and a gluten-free diet should not be initiated until after the biopsy. 
histological processing and then precisely evaluated with the Marsh criteria (regrettably, this is often not done). Patients who go into clinical and serological remission on a gluten-free diet do not need to have their histological remission documented by a further endoscopic procedure.

In complex cases, e.g., in refractory celiac disease, capsule endoscopy can provide further valuable information about atypical or distal small-bowel involvement.

\section{Guideline recommendations of the ESPGHAN}

In 2012, the European Society of Paediatric Gastroenterology, Hepatology, and Nutrition (ESPGHAN) issued a third version of its diagnostic guidelines for celiac disease in children and adolescents $(7, \mathrm{e} 18)$. Some of the main points of this guideline will be discussed briefly in the following paragraphs. New guidelines for both children and adults are due to be issued soon by the German Society for Digestive and Metabolic Diseases (DGVS) and the Society for Pediatric Gastroenterology and Nutrition (GPGE).

\section{Non-invasive diagnostic evaluation}

The new ESPGHAN guidelines include the following molecular-genetic diagnostic parameters (under the applicable restrictions of the German Law on Genetic Diagnosis [Gendiagnostikgesetz]):

- HLA-DQ2 heterodimer in cis configuration (HLADR3-DQA $1 * 0501-\mathrm{DQB} 1 * 0201)$ or in trans configuration (HLA-DR5-DQA1*0505-DQB1*0301 and DR7-DQA $1 * 0201-\mathrm{DQB} 1 * 0202)$ and

- HLA-DQ8 heterodimer (HLA-DR4-DQA1*0301DQB1*0302).

These new diagnostic parameters can be used to rule out celiac disease practically definitively if they are negative. If positive, the diagnosis of celiac disease can be confirmed without a biopsy if all of the following conditions are met:

- classic gastrointestinal manifestation of the disease,

- tenfold elevation of the TG2-IgA titer above the cutoff value,

- confirmation of seropositivity by the detection of anti-endomysium antibodies $(\geq 1: 5)$ in a certified laboratory,

- parent counseling by a pediatric gastroenterologist about the pros and cons of duodenal biopsy,

- clinical and serological remission on a gluten-free diet.

\section{Genetic diseases}

Some genetic diseases (in particular, Down syndrome and Turner syndrome) are associated with celiac disease.
This diagnostic recommendation is based on the finding that high TG2-IgA titers predict villous atrophy (27). As celiac disease is often clinically silent or oligosymptomatic, this constellation will only be found in a very small percentage of persons with the disease.

\section{The screening of persons at risk}

This category includes asymptomatic persons at risk who have an underlying genetic or autoimmune disease, as well as persons with an oligosymptomatic clinical picture suggestive of celiac disease (Box 1). Persons who test positive for HLA-DQ2/8 should undergo TG2-IgA testing every two or three years. If a diagnosis of celiac disease is made, genetic counseling and testing of first-degree relatives for the HLA-DQ2/8 genotype or for anti-TG2 antibodies is recommended.

\section{Gluten challenge}

For children who receive the diagnosis of celiac disease before their second birthday, a gluten challenge is not needed until age 5 (or later) if the diagnostic evaluation has revealed a Marsh II or III lesion in conjunction with positive HLA-DQ2/8 status, and a high TG2-IgA titer and EMA. A gluten challenge under medical supervision is indicated if the patient doubts the diagnosis or if the diagnostic criteria are not unequivocally met. A gluten challenge is a highly informative method of identifying previously unrecognized (misdiagnosed) or latent celiac disease. Before it is carried out, HLA typing and up-to-date duodenal histological findings should be available. A gluten challenge is performed by putting the patient on a normal diet (the equivalent of three to five slices of bread per day) or else in blinded fashion with gluten powder. Depending on the age of the patient, a daily quantity of at least $10-18 \mathrm{~g}$ of gluten should be administered. Serologic testing and duodenal biopsy are performed if symptoms arise during the gluten challenge, or (at most) six months later and then 24 months after the start of the challenge $(7,28)$.

\section{Differential diagnosis}

The differential diagnosis includes infectious (parasitic) and chronic inflammatory bowel diseases (Crohn's disease, autoimmune enteropathy), irritable bowel syndrome, and food allergies. Other possibilities, particularly in infants and preschool children, include rare diarrheal diseases, some of which are congenital (among them disaccharide deficiency, e.g., lactose intolerance, fructose malabsorption, immune defects).
Regular follow-up for persons at elevated risk Persons at elevated risk of developing celiac disease (including first-degree relatives of patients) should undergo regular serologic testing if they are HLA-DQ2/8 positive. 


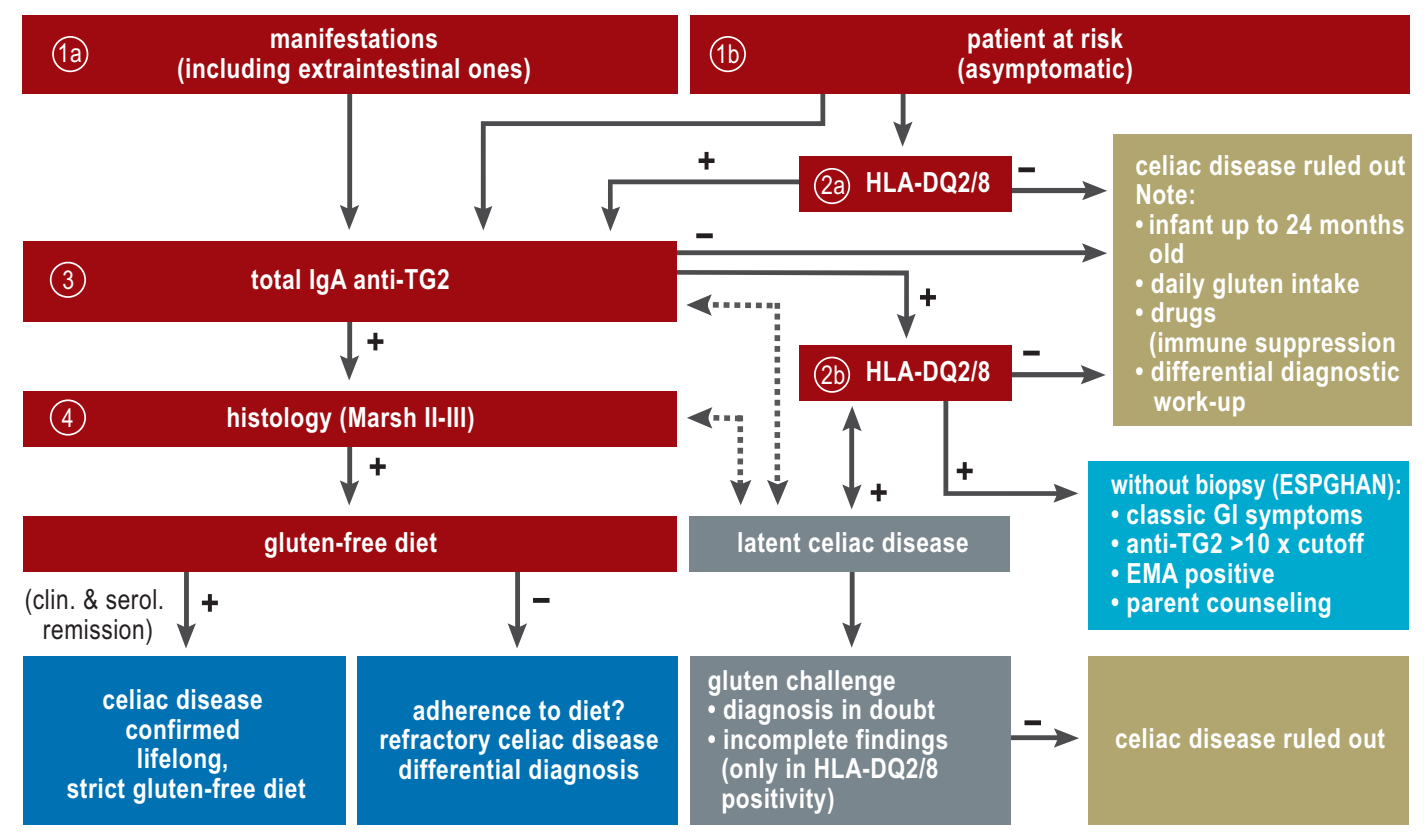

Decision flowchart for the diagnostic evaluation of celiac disease (modified from 22): the diagnostic features that are confirmatory of celiac disease are shown in red, while those that rule it out are shown in brown. In latent celiac disease, it is important to demonstrate HLADQ2/8 positivity and to confirm or exclude the diagnosis both serologically and histologically while the patient continues to consume gluten (dotted arrows). The ESPGHAN criteria enabling the diagnosis of celiac disease without duodenal biopsy in children and adolescents are shown in light blue. Note: in rare cases (e.g., IgA deficiency), the typical antibodies or HLA-DQ2/8 may not be detectable in a patient with celiac disease. It follows that, whenever the clinical manifestations put celiac disease in the differential diagnosis, biopsy is indicated. EMA, anti-endomysium antibodies; $\mathrm{Gl}$, gastrointestinal tract

The differential-diagnostic evaluation should be carried out with targeted laboratory studies and endoscopy and imaging tests if necessary, rationally planned on the basis of the nutritional history, the patient's weight graph, and the clinical findings (Figure 3). In adolescents and adults, the differential diagnosis focuses on non-celiac wheat sensitivity, gluten allergy, histamine intolerance, and intolerance of fermentable oligo-, di-, and monosaccharides and polyols (FODMAP) (Table).

\section{Treatment}

Celiac disease is treated with a strict gluten-free diet (GFD) for life, including abstention from wheat, rye, barley, spelt, kamut, emmer wheat, einkorn wheat, green spelt, and all ready-made products manufactured from the above, such as noodles. Adherence is a difficult matter for most patients, as traces of gluten are found in nearly all refined foods, and a strict GFD inevitably restricts the patient's social activities. When a GFD is initiated, the patient should have professional dietary counseling and should be put in touch with the local celiac disease society. Gluten-free foods are becoming increasingly available, and restaurants now more commonly put gluten-free meals on the menu. The Codex Alimentarius (www.wheat-free.org/celiac-dis ease-codex-alimentarius.html) has lowered the target value for gluten-free foods from 200 to $20 \mathrm{ppm}$. This implies, if the average daily gluten intake is $10-20 \mathrm{~g}$ in $120-250 \mathrm{~g}$ of wheat flour, that less than $10 \mathrm{mg}$ of gluten should be ingested daily (a quantity that is considered

\section{Reliably effective treatment}

A gluten-free diet is a safe and reliably effective treatment for celiac disease. Lifelong strict adherence to the diet is necessary.

\section{Prevention of long-term complications}

A gluten-free diet can prevent long-term complications (osteoporosis, anemia, cancer) and may prevent certain extraintestinal manifestations of the disease. 
The main elements of the differential diagnosis of celiac disease

\begin{tabular}{|c|c|c|c|c|c|}
\hline & Celiac disease & Wheat sensitivity & Wheat allergy & Histamine intolerance & FODMAP intolerance \\
\hline Prevalence & $0.5-1.0 \%(2.5 \%)$ & $3-7 \% ?$ & rare & rare & ? (often mild) \\
\hline History & $\begin{array}{c}\text { symptoms arise upon } \\
\text { introduction of wheat, rye, } \\
\text { barley, spelt, (oats) }\end{array}$ & $\begin{array}{l}\text { improvement on a gluten- } \\
\text { free diet }\end{array}$ & multiple, including gluten & $\begin{array}{l}\text { histamine in fish, cheese, } \\
\text { salami, sauerkraut, } \\
\text { red wine, sparkling wine }\end{array}$ & $\begin{array}{c}\text { FODMAPs } \\
\text { e.g., wheat, rye, garlic, } \\
\text { onions, milk, honey, apples, } \\
\text { pears, mushrooms, } \\
\text { salicylates }\end{array}$ \\
\hline Onset & weeks - years & hours - days & minutes - hours & minutes - hours & hours - days \\
\hline Pathogenesis & $\begin{array}{l}\text { (auto-)immunity } \\
\text { TG2/ATI }\end{array}$ & $\stackrel{?}{?}$ & allergy & diaminoxidase deficiency & $\begin{array}{l}\text { increased intraintestinal } \\
\text { fermentation } \\
\text { microbiota? }\end{array}$ \\
\hline HLA restriction & HLA-DQ2/8 & negative & negative & negative & negative \\
\hline Serology & $\begin{array}{l}\text { IgA-anti TG2, EMA } \\
\text { IgG-DGP }\end{array}$ & negative & $\begin{array}{l}\text { in particular, lgE against } \\
\text { wheat (RAST) }\end{array}$ & negative & negative \\
\hline Histology & Marsh II to III & $\begin{array}{c}\text { negative } \\
\text { (tissue eosinophilia) }\end{array}$ & tissue eosinophilia & negative & negative \\
\hline Clinical features & $\begin{array}{c}\text { (extra-)intestinal } \\
\text { or oligosymptomatic }\end{array}$ & intestinal & (extra-)intestinal & (extra-)intestinal & $\begin{array}{l}\text { intestinal: bloating, } \\
\text { abdominal pain, diarrhea }\end{array}$ \\
\hline Diagnosis & $\begin{array}{c}\text { clinical manifestations, } \\
\text { serology, HLA-DQ2/8, } \\
\text { histology }\end{array}$ & $\begin{array}{l}\text { DBPC challenge } \\
\text { (ideally) }\end{array}$ & $\begin{array}{l}\text { IgE-RAST, prick test, } \\
\text { DBPC challenge }\end{array}$ & $\begin{array}{c}\text { (diaminoxidase } \downarrow \text { ) } \\
\text { (histamine plasma/urine } \uparrow \text { ) } \\
\text { DBPC challenge }\end{array}$ & $\begin{array}{l}\text { DBPC challenge } \\
\text { (ideally) }\end{array}$ \\
\hline Therapy & $\begin{array}{l}\text { strict gluten-free diet } \\
\text { for life }\end{array}$ & $\begin{array}{l}\text { reduction of gluten- } \\
\text { containing foods } \\
\text { (by }>90 \% \text { ?) }\end{array}$ & $\begin{array}{l}\text { strict avoidance of } \\
\text { gluten-containing foods }\end{array}$ & histamine-free diet & low-FODMAP diet \\
\hline Complications & $\begin{array}{c}\text { malabsorption } \\
\text { (long-term complications) } \\
\text { (refractory celiac disease?) }\end{array}$ & negative & $\begin{array}{l}\text { allergic/anaphylactic } \\
\text { reactions }\end{array}$ & $\begin{array}{l}\text { anaphylactoid } \\
\text { reactions }\end{array}$ & negative \\
\hline
\end{tabular}

ATI, amylase/trypsin inhibitors from grains that contain gluten; DBPC, double-blind and placebo-controlled; FODMAP, fermentable oligo-, di-, and monosaccharides and polyols; TG2, tissue transglutaminase; EMA, endomysium antibodiesr; DGP, antibodies against deamidated gliadin peptides; RAST, radioallergosorbent test; wheat sensitivity: the diagnostic criteria for celiac disease are not met, but the manifestations improve on a gluten-free diet

safe). $70 \%$ of patients with classic symptoms have improved symptoms within two weeks of the initiation of a strict gluten-free diet. The serologic features of celiac disease normalize in three to twelve months; intestinal inflammation takes somewhat longer to regress (8). Many guidelines no longer exclude pure oats (i.e., oats that are not contaminated by gluten) from the GFD, recommending instead that tolerance to oats should be tested under medical supervision, as most patients are tolerant $(29$, e19). A gluten-free diet has been shown to protect against all complications of the classic form of celiac disease, including Duhring's dermatitis herpetiformis and osteoporosis. The effect is less clear in other (oligosymptomatic) forms of the disease, but GFD does seem to lessen the severity of mucosal lesions (30).

The findings of an observational study imply that a gluten-free diet can facilitate glycemic control in patients suffering from both celiac disease and type 1 diabetes (31). Beneficial effects of GFD on infertility due to celiac disease, as well as on complications of pregnancy (preterm birth, low birth weight), have also been described (32).

Efforts are now underway to develop effective supportive pharmacotherapy for persons on a strict gluten-free diet $(8,33)$, because patient adherence with GFD is often unsatisfactory (particularly in oligosymptomatic patients) and some patients react to very small

\section{Introduction of gluten to the diet}

Breastfeeding and the introduction of food that contains gluten before the child is weaned have a protective effect against celiac disease.

\section{Differential diagnosis}

Celiac disease must be differentiated from other inflammatory bowel diseases, congenital diarrheal diseases, other types of food intolerances, and irritable bowel syndrome. 
quantities of gluten (as little as $50 \mathrm{mg}$ per day, the equivalent of a single noodle). Potential approaches to drug treatment include:

1. "glutenases" for the degradation of the immunedominant gluten peptides that would otherwise not undergo proteolytic degradation in the intestinal lumen

2. drugs to lower intestinal permeability

3. "gluten vaccination" to induce oral tolerance

4. inhibition of intestinal TG2 with specific TG2 blockers

5. blockade of antigen-presenting HLA-DQ2 (-DQ8)

6. modulation of pro-inflammatory intestinal cytokines with biological agents.

Phase I and II trials of approaches listed in 1. to 3. have shown clinical benefit from the use of a combination of glutenases for patients in remission after the administration of small amounts of gluten. However, it is questionable if the glutenases can degrade the antigenic gluten peptides fast enough to prevent their reaching the upper portion of the small bowel. Vaccination with immune-dominant gluten peptides to induce tolerance remains a speculative form of treatment. The recent development of a specific TG2 inhibitor bears clinical promise.

\section{Prevention}

The protective effect of breastfeeding is well known (e20). Additional protection seems to be derived from the administration of small amounts of gluten during the breastfeeding period, preferably between the ages of four and six months $(34,35, \mathrm{e} 21)$; this hypothesis is now being studied in a prospective clinical trial in multiple European countries. It remains unclear whether the development of, for example, type 1 diabetes in predisposed families can be prevented by cautious gluten administration. A small trial ccarried out on 150 children at risk did not reveal any significant effect (36).

\section{Overview}

Celiac disease is a common autoimmune condition with mainly intestinal, but also extra-intestinal manifestations. Excellent opportunities for accurate diagnosis now exist, above all because of a rapidly improving understanding of the pathogenesis of this disease (autoantibodies against TG2 and HLA-DQ2/8, duodenal histology as classified by Marsh). Thus, even though the clinical spectrum of celiac disease is very broad, an alert clinician can diagnose it early in its course and initiate a glutenfree diet, which usually exerts a protective effect against

\section{Future perspectives}

New treatments for classic and refractory celiac disease are currently being developed. complications of malabsorption and extraintestinal involvement.

Further protective approaches and experimental treatments are now being clinically tested. Persons at elevated risk of developing celiac disease should be screened for it.

\section{Conflict of interest statement}

Prof. Schuppan holds a patent for an anti-TG2 test and receives license fees for its use. He has received reimbursement of conference participation fees and of travel and accommodation expenses, and has been paid for the preparation of continuing medical education events, by the Schär, Merckle Recordati, and Instrumentation Laboratory companies.

Prof. Zimmer states that he has no conflict of interest.

Manuscript submitted on 2 May 2013, revised version accepted on 11 September 2013.

Translated from the original German by Ethan Taub, M.D.

\section{REFERENCES}

1. Dieterich W, Ehnis T, Bauer M, et al.: Identification of tissue transglutaminase as the autoantigen of celiac disease. Nat Med 1997; 3 : 797-801.

2. Mustalahti K, Catassi C, Reunanen A, et al.: The prevalence of celiac disease in Europe: results of a centralized, international mass screening project. Ann Med 2010; 42: 587-95.

3. Rostom A, Dube C, Cranney A, et al.: Celiac Disease. Evidence Report/ Technology Assessment No. 104. Rockville (MD): Agency for Healthcare Research and Quality (US); 2004.

4. Hill ID, Dirks MH, Liptak GS, et al.: Guideline for the diagnosis and treatment of celiac disease in children: recommendations of the North American Society for Pediatric Gastroenterology, Hepatology and Nutrition. Journal of Pediatric Gastroenterology and Nutrition 2005; 40 : $1-19$.

5. Rostom A, Murray JA, Kagnoff MF: American Gastroenterological Association (AGA) Institute technical review on the diagnosis and management of celiac disease. Gastroenterology 2006; 131: 1981-2002.

6. (UK) CfCPaN: Coeliac disease: recognition and assessment of coeliac disease. London: National Institute for Health and Clinical Excellence (UK)2009.

7. Husby S, Koletzko S, Korponay-Szabo IR, et al.: European Society for Pediatric Gastroenterology, Hepatology, and Nutrition guidelines for the diagnosis of coeliac disease. Journal of Pediatric Gastroenterology and Nutrition 2012; 54: 136-60.

8. Schuppan D, Junker Y, Barisani D: Celiac disease: from pathogenesis to novel therapies. Gastroenterology 2009; 137: 1912-33.

9. Zimmer KP, Fischer I, Mothes T, et al.: Endocytotic segregation of gliadin peptide 31-49 in enterocytes. Gut 2010; 59: 300-10.

10. Junker Y, Zeissig S, Kim SJ, et al.: Wheat amylase trypsin inhibitors drive intestinal inflammation via activation of toll-like receptor 4 . The Journal of Experimental Medicine 2012; 209: 2395-408.

11. Reilly NR, Green PH: Epidemiology and clinical presentations of celiac disease. Seminars in immunopathology 2012; 34: 473-8.

12. Barada K, Abu Daya H, Rostami K, Catassi C: Celiac disease in the developing world. Gastrointestinal endoscopy clinics of North America 2012; 22: 773-96.

13. Henker J, Losel A, Conrad K, Hirsch T, Leupold W: Prävalenz der asymptomatischen Zöliakie bei Kindern und Erwachsenen in der Region Dresden. [Prevalence of asymptommatic coeliac disease in children and adults in the Dresden region of Germany]. Deutsche Medizinische Wochenschrift 2002; 127: 1511-5.

14. Croese J, Gaze ST, Loukas A: Changed gluten immunity in celiac dis ease by Necator americanus provides new insights into autoimmunity. International Journal for Parasitology 2013; 43: 275-82.

15. Stene LC, Honeyman MC, Hoffenberg EJ, et al.: Rotavirus infection frequency and risk of celiac disease autoimmunity in early childhood: a longitudinal study. The American Journal of Gastroenterology 2006; 101: 2333-40.

16. Zimmer KP: Klinische Bedeutung nichtklassischer Zöliakieformen Dt Ärztebl 2001; 98: A 3285-3292 [Heft 49]. 
17. Ventura A, Magazzu G, Greco L: Duration of exposure to gluten and risk for autoimmune disorders in patients with celiac disease. SIGEP Study Group for Autoimmune Disorders in Celiac Disease. Gastroenterology 1999; 117: 297-303

18. Dittmar M, Kahaly GJ: Genetics of the autoimmune polyglandular syndrome type 3 variant. Thyroid: Official Journal of the American Thyroid Association 2010; 20: 737-43.

19. Roshan B, Leffler DA, Jamma S, et al.: The incidence and clinical spectrum of refractory celiac disease in a north american referral center. The American Journal of Gastroenterology 2011; 106: 923-8.

20. Rubio-Tapia A, Murray JA: Classification and management of refractory coeliac disease. Gut 2010; 59: 547-57.

21. Malamut G, Meresse B, Cellier C, Cerf-Bensussan N: Refractory celiac disease: from bench to bedside. Seminars in immunopathology 2012; 34: 601-13

22. Leffler DA, Schuppan D: Update on serologic testing in celiac disease. The American Journal of Gastroenterology 2010; 105: 2520-4.

23. Simell S, Hoppu S, Hekkala A, et al.: Fate of five celiac disease-associated antibodies during normal diet in genetically at-risk children observed from birth in a natural history study. The American Journal of Gastroenterology 2007; 102: 2026-35.

24. Richter T, Bossuyt X, Vermeersch $P$, et al.: Determination of $\lg G$ and $\lg A$ antibodies against native gliadin is not helpful for the diagnosis of coeliac disease in children up to 2 years old. Journal of Pediatric Gastroenterology and Nutrition 2012; 55: 21-5.

25. Oberhuber G, Caspary WF, Kirchner T, Borchard F, Stolte M, German Society for Pathology Task Force on Gastroenterologic P: Empfehlungen zur Zöliakie-/Spruediagnostik (Arbeitsgemeinschaft für gastroenterologische Pathologie der Deutschen Gesellschaft für Pathologie). [Diagnosis of celiac disease and sprue. Recommendations of the German Society for Pathology Task Force on Gastroenterologic Pathology] Der Pathologe 2001; 22: 72-81.

26. Chang F, Mahadeva U, Deere H: Pathological and clinical significance of increased intraepithelial lymphocytes (IELs) in small bowel mucosa. APMIS 2005; 113: 385-99.

27. Dahlbom I, Korponay-Szabo IR, Kovacs JB, Szalai Z, Maki M, Hansson T: Prediction of clinical and mucosal severity of coeliac disease and dermatitis herpetiformis by quantification of IgA/lgG serum antibodies to tissue transglutaminase. Journal of Pediatric Gastroenterology and Nutrition 2010; 50: 140-6.

28. Leffler D, Schuppan D, Pallav K, et al.: Kinetics of the histological, serological and symptomatic responses to gluten challenge in adults with coeliac disease. Gut 2012

29. Zimmer KP: Nutrition and celiac disease. Current problems in pediatric and adolescent health care 2011; 41: 244-7.

30. Elfstrom P, Granath F, Ekstrom Smedby K, et al.: Risk of lymphoproliferative malignancy in relation to small intestinal histopathology among patients with celiac disease. Journal of the National Cancer Institute 2011; 103: 436-44.

31. Hansen D, Brock-Jacobsen B, Lund E, et al.: Clinical benefit of a glutenfree diet in type 1 diabetic children with screening-detected celiac disease: a population-based screening study with 2 years' follow-up. Diabetes care 2006; 29: 2452-6.

32. Khashan AS, Henriksen TB, Mortensen PB, et al.: The impact of maternal celiac disease on birthweight and preterm birth: $A$ Danish population-based cohort study. Hum Reprod 2010; 25: 528-34

33. Mukherjee R, Kelly CP, Schuppan D: Nondietary therapies for celiac disease. Gastrointestinal endoscopy clinics of North America 2012; 22 811-31.

34. Norris JM, Barriga K, Hoffenberg EJ, et al.: Risk of celiac disease autoimmunity and timing of gluten introduction in the diet of infants at increased risk of disease. JAMA 2005; 293: 2343-51.
35. Ivarsson A, Persson LA, Nystrom L, et al.: Epidemic of coeliac disease in Swedish children. Acta Paediatr 2000; 89: 165-71.

36. Hummel S, Pfluger M, Hummel M, Bonifacio E, Ziegler AG: Primary dietary intervention study to reduce the risk of islet autoimmunity in children at increased risk for Type 1 Diabetes: The BABYDIET study. Diabetes care 2011

37. Bianchi ML, Bardella MT: Bone in celiac disease. Osteoporosis international: a journal established as result of cooperation between the European Foundation for Osteoporosis and the National Osteoporosis Foundation of the USA 2008; 19: 1705-16.

38. Kane EV, Newton R, Roman E: Non-Hodgkin lymphoma and glutensensitive enteropathy: estimate of risk using meta-analyses. Cancer Causes Control 2011.

39. Metzger MH, Heier M, Maki M, et al.: Mortality excess in individuals with elevated IgA anti-transglutaminase antibodies: the KORA/MONICA Augsburg cohort study 1989-1998. European Journal of Epidemiology 2006; 21: 359-65.

40. Rubio-Tapia A, Kyle RA, Kaplan EL, et al.: Increased prevalence and mortality in undiagnosed celiac disease. Gastroenterology 2009; 137: 88-93.

\section{Corresponding author}

Prof. Dr. med. Klaus-Peter Zimmer

Abteilung Allgemeine Pädiatrie \& Neonatologie, Zentrum für Kinderheilkunde

und Jugendmedizin, Universitätsklinikum Giessen und Marburg GmbH

Justus-Liebig-Universität, Feulgenstr. 12, D-35385 Giessen, Germany

klaus-peter.zimmer@paediat.med.uni-giessen.de

@

For eReferences please refer to:

www.aerzteblatt-international.de/ref4913

Case Illustration, eTable:

www.aerzteblatt-international.de/13m0835

Further Information on GME

This article has been certified by the North Rhine Academy for Postgraduate and Continuing Medical Education. Deutsches Ärzteblatt provides certified continuing medical education (CME) in accordance with the requirements of the Medical Associations of the German federal states (Länder). CME points of the Medical Associations can be acquired only through the Internet, not by mail or fax, by the use of the German version of the CME questionnaire. See the following website: cme.aerzteblatt.de.

Participants in the CME program can manage their CME points with their 15-digit "uniform CME number" (einheitliche Fortbildungsnummer, EFN). The EFN must be entered in the appropriate field in the cme.aerzteblatt.de website under "meine Daten" ("my data"), or upon registration. The EFN appears on each participant's CME certificate.

The present CME unit can be accessed until 9 March 2014

The CME unit "The Febrile Child" (Issue 45/2013) can be accessed until 9 February 2014.

The CME unit "Common Causes of Poisoning" (Issue 41/2013) can be accessed until 12 January 2014.

The CME unit "Degenerative Lumbar Spinal Stenosis in Older People" (Issue 37/2013) can be accessed until 8 December 2013. 


\section{Please answer the following questions to participate in our certified Continuing Medical Education program. Only one answer is possible per question. Please select the answer that is most appropriate.}

Question 1

What induces the manifestations of celiac disease?
a) food that contains gluten
b) a selective IgA excess
c) an allergic lesion of the intestinal mucosa
d) animal-derived proteins
e) lactose intolerance

\section{Question 2}

What percentage of patients with classic celiac disease have improved symptoms and signs after two weeks of strict adherence to a gluten-free diet?
a) $50 \%$
b) $60 \%$
c) $70 \%$
d) $80 \%$
e) $90 \%$

\section{Question 3}

Which of the following autoimmune diseases are associated wtih celiac disease?

a) type 1diabetes, glomerulonephritis, psoriasis

b) type 2 diabetes, multiple sclerosis, myasthenia gravis

c) type 1 diabetes, ulcerative colitis, systemic lupus erythematosus

d) type 1 diabetes, autoimmune thyroiditis, autoimmune hepatitis

e) type 2 diabetes, autoimmune enteropathy, Crohn's disease
Question 6

A mother of a 4-year-old boy recently diagnosed with celiac disease comes to you for advice. She tells you her other two children are well. What should you recommend?

a) moleccular-genetic determination of HLA-DQ2/8 in her other two children after genetic counseling

b) gastroduodenoscopy with duodenal biopsy

c) a low-FODMAP diet

d) anti-gliadin IgA measurement in saliva

e) stool screening for anti-gliadin antibodies

\section{Question 7}

Which of the following foods contains gluten?
a) potatoes
b) quinoa
c) amaranth
d) wild rice
e) noodles

\section{Question 8}

Which of the following apparently affords additional protection against celiac disease?

a) gluten-free food till the age of 12 months

b) vegetarian food till the age of 8 months

c) vegan maternal diet during pregnancy

d) unrestricted maternal diet during pregnancy

e) the introduction of small amounts of gluten along with breastfeeding between the ages of 4 and 6 months

Question 9

What diagnostic parameter(s) should be checked over time in a patient on a gluten-free diet?
a) normalization of the duodenal mucosa
b) clinical and serological remission
c) clinical, serological, and histological remission
d) clinical remission
e) serological remission

\section{Question 5}

Which of the following is a diagnostic criterion for celiac disease?
a) HLA-B27
b) crypt abscesses of the intestinal mucosa
c) anti-DNA antibodies
d) antibodies against native gliadin
e) antibodies against tissue transglutaminase (TG2)

\section{Question 10}

What is the autoantigen of celiac disease?
b) Th0
c) TG2
d) CTL
e) Th2

a) myelin basic protein 


\title{
CONTINUING MEDICAL EDUCATION
}

\section{The Diagnosis and Treatment of Celiac Disease}

\author{
Detlef Schuppan, Klaus-Peter Zimmer
}

\section{EREFERENCES}

e1. Hardwick C: Prognosis in coeliac disease: A Review of SeventyThree Cases. Archives of disease in childhood 1939; 14: 279-94.

e2. van Berge-Henegouwen GP, Mulder CJ: Pioneer in the gluten free diet: Willem-Karel Dicke 1905-1962, over 50 years of gluten free diet. Gut 1993; 34: 1473-5.

e3. Rampertab SD, Pooran N, Brar P, Singh P, Green PH: Trends in the presentation of celiac disease. The American journal of medicine 2006; 119: 355 e9-14.

e4. Shan L, Molberg 0, Parrot I, et al.: Structural basis for gluten intolerance in celiac sprue. Science 2002; 297: 2275-9.

e5. Giersiepen K, Lelgemann M, Stuhldreher N, et al.: Accuracy of diagnostic antibody tests for coeliac disease in children: summary of an evidence report. Journal of pediatric gastroenterology and nutrition 2012; 54: 229-41.

e6. Lurz E, Scheidegger U, Spalinger J, Schoni M, Schibli S: Clinical presentation of celiac disease and the diagnostic accuracy of serologic markers in children. European journal of pediatrics 2009; 168: 839-45.

e7. Stordal K, Bakken IJ, Suren P, Stene LC: Epidemiology of coeliac disease and co-morbidity in Norwegian Children. Journal of pediatric gastroenterology and nutrition 2013.

e8. Kratzer W, Kibele M, Akinli A, et al.: Prevalence of celiac disease in Germany: a prospective follow-up study. World journal of gastroenterology: WJG 2013; 19: 2612-20.

e9. Whyte LA, Jenkins HR: The epidemiology of coeliac disease in South Wales: a 28-year perspective. Archives of disease in childhood 2013; 98: 405-7.

e10. Hurley JJ, Lee B, Turner JK, Beale A, Jenkins HR, Swift GL: Incidence and presentation of reported coeliac disease in Cardiff and the Vale of Glamorgan: the next 10 years. European journal of gastroenterology \& hepatology 2012; 24: 482-6.

e11. Vivas S, Ruiz de Morales JM, Fernandez M, et al.: Age-related clinical, serological, and histopathological features of celiac disease. The American journal of gastroenterology 2008; 103: 2360-5; quiz 6. e12. Telega G, Bennet TR, Werlin S: Emerging new clinical patterns in the presentation of celiac disease. Archives of pediatrics \& adolescent medicine 2008; 162: 164-8.

e13. Ludvigsson JF, Leffler DA, Bai JC, et al.: The Oslo definitions for coeliac disease and related terms. Gut 2013; 62: 43-52.

e14. Chandesris MO, Malamut G, Verkarre V, et al.: Enteropathyassociated T-cell lymphoma: a review on clinical presentation, diagnosis, therapeutic strategies and perspectives. Gastroenterologie clinique et biologique 2010; 34: 590-605.

e15. Zelnik N, Pacht A, Obeid R, Lerner A: Range of neurologic disorders in patients with celiac disease. Pediatrics 2004; 113 : 1672-6.

e16. Richter $T$, Bossuyt $X$, Vermeersch $P$, et al.: Determination of IgG and IgA antibodies against native gliadin is not helpful for the diagnosis of coeliac disease in children up to 2 years old. Journal of pediatric gastroenterology and nutrition 2012; 55: 21-5.

e17. Marsh MN: Gluten, major histocompatibility complex, and the small intestine. A molecular and immunobiologic approach to the spectrum of gluten sensitivity ('celiac sprue'). Gastroenterology 1992; 102: 330-54.

e18. Koletzko S: Diagnose und Therapie der Zöliakie im Kindesalter. Monatsschr Kinderheilkd 2013; 161: 63-798.

e19. Rashid M, Butzner D, Burrows V, et al.: Consumption of pure oats by individuals with celiac disease: a position statement by the Canadian Celiac Association. Canadian journal of gastroenterology = Journal canadien de gastroenterologie 2007; 21: 649-51.

e20. Akobeng AK, Ramanan AV, Buchan I, Heller RF: Effect of breast feeding on risk of coeliac disease: a systematic review and metaanalysis of observational studies. Archives of disease in childhood 2006; 91: 39-43.

e21. Szajewska H, Chmielewska A, Piescik-Lech M, et al.: Systematic review: early infant feeding and the prevention of coeliac disease. Alimentary pharmacology \& therapeutics 2012; 36: 607-18. 
MEDICINE

\section{GTABLE}

The most common manifestations of celiac disease, in percent

\begin{tabular}{l|c|c}
\hline Diarrhea & $\begin{array}{c}\text { Children / adolescents } \\
\text { (251 subjects) }\end{array}$ & $\begin{array}{c}\text { Adults } \\
\text { (359 subjects) }\end{array}$ \\
\hline Abdominal pain & $28-55$ & $18-47$ \\
\hline Abdominal bloating & $12-33$ & $18-28$ \\
\hline Anemia & $12-29$ & 26 \\
\hline Failure to thrive & $2-19$ & $38-51$ \\
\hline Growth disturbance & $13-26$ & $34^{*}$ \\
\hline
\end{tabular}

*weight loss

(modified from 11, e11, e12 [percentages vary widely depending, among others, on age, patient group, and application of iindications for screening]) 


\title{
The Diagnosis and Treatment of Celiac Disease
}

\author{
Detlef Schuppan, Klaus-Peter Zimmer
}

\section{Case Illustration}

seven-year-old girl with normal development to date and no history of food intolerance is taken to the pediatric outpatient pulmonary clinic by her parents because of nocturnal hemoptysis that has been occurring for several weeks. She has needed multiple blood transfusions because of recurrent drops in her hemoglobin concentration, down to a minimum of $3.8 \mathrm{~g} / \mathrm{dL}$. Her vital capacity is also low, at $46 \%$ of normal. Bronchial lavage reveals ironladen macrophages, and a diagnosis of pulmonary hemosiderosis is made. In the further diagnostic work-up, Heiner syndrome is excluded, but positive anti-endomysium and tissue transglutaminase antibodies are found. Duodenal biopsy via esophagogastroduodenoscopy reveals a Marsh III lesion. The child has no diarrhea or other gastrointestinal symptoms. She is put on a gluten-free diet, whereupon hemoptysis ceases and her pulmonary function returns to normal. Within six months, the typical antibodies of celiac disease are no longer detectable. Her hemoglobin concentration is stable; the only abnormal laboratory value is now a high ferritin concentration (500-600 ng/mL, a consequence of blood transfusions). There is no need to confirm healing of the duodenal mucosa by biopsy or to perform a gluten challenge. The patient is HLA-DQ2 positive. The physicians tell her parents that she will have to adhere strictly to a gluten-free diet for life, and that she should return annually for outpatient follow-up.

Cite this as:

Schuppan D, Zimmer KP: The diagnosis and treatment of celiac disease. Dtsch Arztebl Int 2013; 110(49): 835-46. D0I: 10.3238/arztebl.2013.0835 